\title{
Hematopoietic Stem Cell Transplantation for Malignant Solid Tumors in Children
}

\author{
Toshihisa Tsuruta \\ Department of Clinical Examination \\ National Hospital Organization Kumamoto Medical Center \\ Japan
}

\section{Introduction}

The prognosis of malignant solid tumors in children has been improved by multidisciplinary therapy involving surgery, radiotherapy and chemotherapy. High-dose chemotherapy (HDC) followed by autologous (Auto) or allogeneic (Allo) hematopoietic stem cell transplantation (HSCT) has contributed significantly to improvements in the prognosis of high-risk chemosensitive tumors. It has been utilized in many kinds of pediatric malignancies, not only hematopoietic tumors but also solid tumors such as neuroblastoma, brain tumors, Ewing's sarcoma, osteosarcoma, Wilms' tumor, rhabdomyosarcoma, hepatoblastoma, and retinoblastoma. Fig, 1 shows the numbers of cases in which HSCT was used for pediatric solid tumors in Japan. When HSCT is utilized in patients with malignant solid tumors, there are several treatment objectives. First, it can be intended as a curative treatment acting on the minimal residual malignant cells after

Neuroblastoma $\square$ Brain tumors $\square$ Ewing's sarcoma $\square$ Rhabdomyosarcoma $\square$ Wilms' tumor $\square$ Others

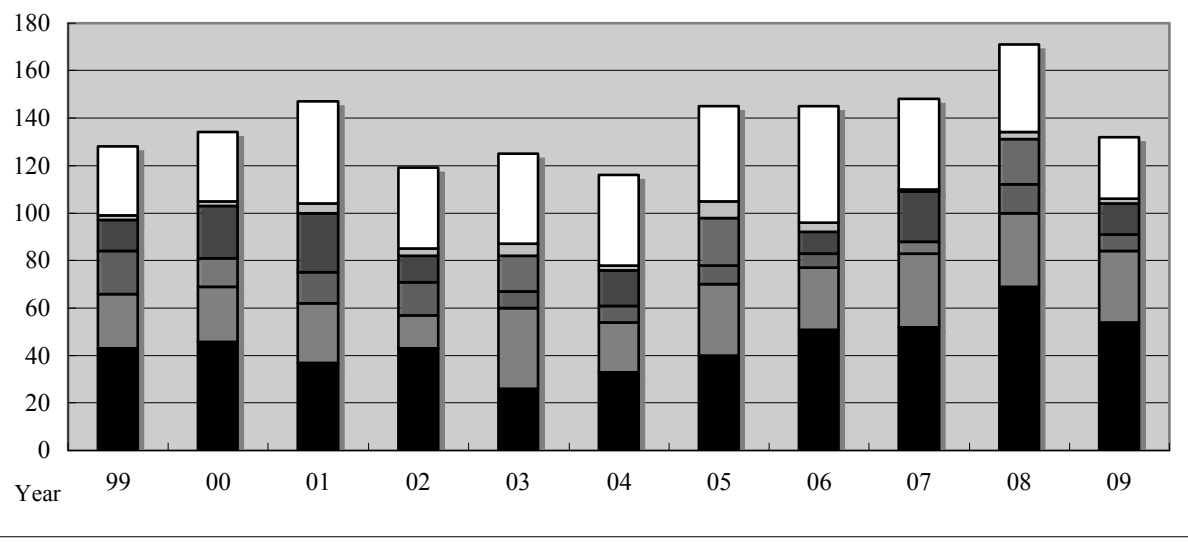

Fig. 1. The number of hematopoietic stem cell transplants for pediatric solid tumors in Japan. 
conventional therapies. Second, it can be used in refractory or relapsed disease when conventional doses of anti-tumor drugs may have not reached or killed tumor cells. Third, it can be used for the immunological effect of Allo HSCT. Allo HSCT grafts sometimes have immunological anti-tumor effects called graft versus tumor (GVT) effects. Nonmyeloablative conditioning regimens with Allo HSCT for solid tumors are one such example. Furthermore, tandem HSCT to increase dose intensity and HSCT with targeted radionuclide therapy have been studied clinically. In this chapter, I review the literature on HSCT for malignant solid tumors, especially non-hematopoietic tumors in children according to tumor type and consider future therapy.

Fig. 1. The Japan Society for Hematopoietic Cell Transplantation Office of Nationwide Survey, (March 2011), The Japan Society for Hematopoietic Cell Transplantation Annual Report of Nationwide Survey 2010, p. 60

\section{Neuroblastoma}

Neuroblastoma (NB) is the most common extracranial solid tumor of childhood. The prognostic indicators of NB are age at diagnosis, tumor stage as classified by the International NB Staging System (INSS) (Brodeur et al., 1993), amplification of the MYCN oncogene (Brodeur et al., 1984), and histological findings (Shimada et al., 1999). HSCT has been performed for high-risk NB, characterized as stage IV by INSS, stage III with other negative prognostic factors e.g. unfavorable histology (Shimada system), or any stage with amplification of the MYCN oncogene (Matthay et al., 1999; Weinstein et al., 2003).

\subsection{Stem cell sources for HSCT in NB}

Bone marrow transplantation (BMT) and peripheral blood stem cell transplantation (PBSCT) following mobilization by granulocyte colony-stimulating factor (G-CSF) are available for Auto HSCT in patients with NB (Fish \& Grupp, 2008). Since NB cells infiltrate the bone marrow (BM) more frequently than peripheral blood (Cohn et al., 1997; Trager et al., 2003), and PB stem cells provide faster hematopoietic recovery, PB stem cells are used more often than BM cells in Auto HSCT (Fish \& Grupp, 2008). Allo umbilical cord blood transplantation (CBT) from an unrelated donor, as well as Allo BMT or PBSCT, have also been performed in NB patients (Vanlemmens et al., 1992; Wagner, 1993).

\subsection{CD34+ positive selection of HSCT for NB}

Since minimal residual disease (MRD) in PBSC, as evaluated by anti-GD2 immunofluorescence or tyrosine hydroxylase reverse transcriptase-polymerase chain reaction (RT-PCR), is one of the prognostic factors of NB, the positive selection of CD34+ Auto PB stem cells has been studied in NB (Marabelle et al., 2011). MRD has been shown to exist in the CD34 negative fraction with most NB cells removed by the selection. CD34+ positive selection does not affect long-term hematopoiesis although immune recovery is delayed. Treatment with 13-cis-retinoic acid therapy after HSCT is thought to be effective for MRD (Marabelle et al., 2011).

\subsection{Conditioning regimens of HSCT for NB}

As a preparative regimen prior to Auto or Allo HSCT for patients with NB, fractionated total body irradiation (TBI) or local irradiation is often utilized (Kushner et al., 1991). TBI- 
containing regimens to treat NB have acceptable toxicity and are as effective as non-TBI preparative regimens (Kamani et al., 1996; McCowage et al., 1995). Patients who receive TBI have long-term adverse effects such as growth failure (Hovi et al., 1999) and severe disturbances of dental development (Holtta et al., 2002) more often than patients who receive non-TBI-containing regimens. Many kinds of regimens, especially melphalan-based regimens with or without TBI, have been studied as conditioning regimens for Auto HSCT in high-risk NB patients (Yalcin et al., 2011). Recently, a study of 36 patients with high-risk NB (median age at transplantation: 3 years, range: 0.7-14 years) who received high-dose busulfan and melphalan as the conditioning regimen for Auto HSCT was reported. No toxic deaths were observed. With a median follow-up of 55 months, progression-free survival (PFS) was $57 \pm 9 \%$ for the whole group and patients who achieved early complete remission (CR) following transplantation (3 months post-transplantation) had a better outcome than those who did not (PFS: $91 \pm 6 \%$ vs. $9 \pm 8 \%$ ). They also showed younger patients with no $1 \mathrm{p}$ deletions had better outcomes (Molina et al., 2011).

\subsection{Randomized studies of HSCT for NB}

The Children's Cancer Group (CCG) in the US first reported a randomized trial involving Auto HSCT. High-risk NB patients between 1 to 18 years of age who received five cycles of initial chemotherapy (doxorubicin $30 \mathrm{mg} / \mathrm{m}^{2}$, etoposide $100 \mathrm{mg} / \mathrm{m}^{2}$ daily for 2 days, and cyclophosphamide $1000 \mathrm{mg} / \mathrm{m}^{2}$ daily for 2 days) who showed no disease progression were randomized to myeloablative therapy (carboplatin $1000 \mathrm{mg} / \mathrm{m}^{2}$, etoposide $640 \mathrm{mg} / \mathrm{m}^{2}$, melphalan $140 \mathrm{mg} / \mathrm{m}^{2}$ ), TBI (333 cGy daily for 3 days), or to three cycles of continuation chemotherapy (cisplatin $160 \mathrm{mg} / \mathrm{m}^{2}$, etoposide $500 \mathrm{mg} / \mathrm{m}^{2}$ and doxorubicin $40 \mathrm{mg} / \mathrm{m}^{2}$ ). The mean event-free survival (Fangusaro et al.) rate three years after randomization was significantly better among the 189 patients who were assigned to undergo transplantation than among the 190 patients assigned to receive conventional chemotherapy ( $34 \pm 4 \%$ vs. 22 $\pm 4 \%, p=0.034$ ) (Matthay et al., 1999) .

There are two reported randomized trials from Europe. The European NB Study Group (ENSG) demonstrated the value of melphalan myeloablative therapy. In their study, 167 children with stage III or IV (44 stage III and stage IV from 6 to 12 month old at diagnosis, 123 stage IV $>1$ years old) were treated by initial induction chemotherapy consisting of vincristine, cisplatin, epipodophyllotoxin, and cyclophosphamide and surgical excision of the primary tumor. Ninety patients were achieved complete or good partial responses, and then $65(72 \%)$ children were actually randomized either to high-dose melphalan (180 $\mathrm{mg} / \mathrm{m}^{2}$ ) with Auto bone marrow support or to no further treatment. The 5-year EFS with median follow-up from randomization of 14.3 years was 38\% (95\% confidence interval (CI): $24-54 \%$ ) in the melphalan-treated group and $27 \%$ (95\% CI: $12-42 \%$ ) in the group who did not receive melphalan. Although this difference was not statistically significant, the outcome of 48 randomized stage IV patients $>1$ year at diagnosis was significantly better in the melphalan-treated group (5-year EFS 33\% vs. 17\%, $p=0.01$ ) (Pritchard et al., 2005).

In Germany, a randomized study involving myeloablative HDC with Auto HSCT versus oral maintenance chemotherapy was conducted. Two hundred and ninety-five patients with high-risk NB (i.e. stage IV or MYCN amplified tumors) were randomly assigned to myeloablative HDC (melphalan, etoposide, and carboplatin) with Auto HSCT ( $=149)$ or oral maintenance chemotherapy with cyclophosphamide $(n=146)$. The 3-year EFS in the HDC group (47\%, 95\% CI: $38-55 \%)$ was better than that (30\%, 95\% CI: $45-62 \%)$ in the oral 
maintenance therapy group $(p=0.0221)$, but there was no difference in overall survival (OS) (62\%; $95 \%$ CI: $54-70 \%$ vs. $53 \%$; 95\% CI: $45-62 \%$; $p=0.0875)$. In the HDC group, five patients died from acute complications related to HDC, but no patients on oral maintenance therapy died from acute treatment-related toxic effects (Berthold et al., 2005).

\subsection{MYCN Amplification in NB and HSCT}

In patients with stage II or III neuroblastoma with MYCN amplification, the prognosis of patients who received high-dose busulfan $\left(600 \mathrm{mg} / \mathrm{m}^{2}\right)$ and melphalan $\left(140 \mathrm{mg} / \mathrm{m}^{2}\right)(\mathrm{n}=12)$ is better than that of patients who received conventional chemotherapy (carboplatin, etoposide, vincristine, cyclophosphamide, and doxorubicin), radiotherapy, or both $(\mathrm{n}=20)$. The 6-year OS was significantly different $(25 \pm 10 \%$ vs. $83 \pm 11 \%$; $p=0.004)$ (Laprie et al., 2004).

\subsection{Tandem HSCT for NB}

Scheduled multiple cycles of (tandem) Auto HSCT for high-risk NB were reported first by Philip et al. They used two different regimens for advanced NB and harvested bone marrow twice before and after first BMT. The harvested bone marrow cells were purged in vitro by an immunomagnetic technique. The first regimen was a combination of tenoposid, carmustine, and cisplatinium (or carboplatin). The second regimen consisted of vincristine, melphalan, and TBI. This double HSCT achieved a prolonged relapse free survival (Philip et al., 1993). There are several reports of double Auto HSCT with one course of TBI (George et al., 2006; Sung et al., 2007) or without TBI (Grupp et al., 2000). Central nervous system relapse and secondary malignancies are rare in patients who receive tandem HSCT (George et al., 2006), although there is an increase in treatment-related deaths after the second HSCT (Grupp et al., 2000; Sung et al., 2007) and a higher rate of late adverse effects including growth hormone deficiency, dental problems, osteochondromas, and hearing deficiencies (Hobbie et al., 2008). Children's Healthcare of Atlanta performed a study comparing single versus tandem HSCT for high-risk NB. There were 28 patients who received a single HSCT and 56 who received tandem HSCT. Tandem HSCT had a significantly improved 4-year EFS $(59.3 \pm 6.7 \%$ vs. $26.8 \pm 9.2 \%, p=0.01)$ and OS $(70.6 \pm 9.2 \%$ vs. $44.7 \pm 11.2 \%, p=0.06)$ when compared with single HSCT (Qayed et al., 2011).

Triple-tandem HDC with PBSCT for high-risk NB was reported by two different groups. The conditioning regimens of the first first consisted of two courses of carboplatin (667 $\mathrm{mg} / \mathrm{m}^{2}$ daily for 2 days) and etoposide ( $1000 \mathrm{mg} / \mathrm{m}^{2}$ daily for 2 days) following one course of thiotepa (300 mg/m² daily for 3 days) and cyclophosphamide $(60 \mathrm{mg} / \mathrm{kg}$ daily for 3 days). Seventeen patients were able to complete all three cycle of HSCT. The 3-year EFS and survival were $57 \pm 11 \%$ and $79 \pm 10 \%$, respectively (Kletzel et al., 2002). The study by the Children's Oncology Group in the US involved patients with stage IV NB receiving three cycles of interpatient dose escalating carboplatin $\left(800\right.$ to $\left.1000 \mathrm{mg} / \mathrm{m}^{2}\right)$, cyclophosphamide $(4$ $\left.\mathrm{g} / \mathrm{m}^{2}\right)$ and etoposide $\left(600 \mathrm{mg} / \mathrm{m}^{2}\right)$. The overall 3-year EFS and OS rates were $20 \pm 10 \%$ and $26 \pm 11 \%$, respectively (Bensimhon et al., 2010).

\subsection{Allo HSCT for NB}

Allo HSCT with TBI for NB has been attempted more than a quarter century ago (August et al., 1984). Although the graft contains no contamination of tumor cells, initial studies of conventional Allo HSCT failed to show a clear clinical benefit with a high ratio of treatment- 
related mortality (TRM) and graft versus host diseases (GVHD) (Evans et al., 1994; Ladenstein et al., 1994; Matthay et al., 1994). However, the development of supportive care and the establishment of Allo HSCT for leukemia had renewed interest in Allo immunity for various malignant cells that is described as a graft versus tumor effect (GVT) (Pedrazzoli et al., 2002). Cytotoxic T-lymphocytes can target antigens found on malignant cells. These antigens include linage-restricted antigens found on tumors of similar origin and on related normal cells (e.g., GD2 ganglioside expressed in NB), antigens found on tumors of different origins but not on normal tissue, and tumor-specific antigens produced by mutant genes within the tumor (Navid et al., 2009).

Clinical GVT was first described in a patient with NB who received HSCT from a HLA haplo-identical donor. Although the patient received further chemotherapy after the Allo HSCT and the response was not correlated to GVHD, the patient entered and sustained complete remission for 4 years (Inoue et al., 2003). A more recent report shows clinical GVT for NB is correlated with GVHD in a patient who underwent a reduced intensity Allo HSCT (Marabelle et al., 2007). In mice, efficient GVT for NB could be induced by donor lymphocyte infusion or immunomodulation with dendritic cells after Allo HSCT in the absence of GVHD (Ash et al., 2009; Ash et al., 2010). Allo CBT for NB was also performed since the early 1990s in three patients with advanced NB with highly amplified MYCN (Vanlemmens et al., 1992; Wagner, 1993). After receiving Auto HSCT followed by Allo CBT, they have maintained disease-free survival (DFS) for 37 to 60 months without severe acute complications (Goi et al., 2011). Recently, a reduced-intensity conditioning regimen (cyclophosphamide $50 \mathrm{mg} / \mathrm{kg}$, fludarabine $40 \mathrm{mg} / \mathrm{m}^{2}$ daily for two days, TBI 200 cGy, and rabbit anti-thymocyte globulin $2.5 \mathrm{mg} / \mathrm{kg}$ daily for two days) followed by unrelated CBT was studied for patients with relapsed NB. Although all patients progressed after transplant (median: 55 days, range: 26 to 180 days), natural killer (NK) cell counts were normal within 2 months with no evidence of GVHD, whereas the T-cell recovery was slower. These results show the possibility of treating patients with MRD after transplant with less intensive immunosuppression and adding NK-cell based post-transplant immunotherapy (Jubert et al., 2011).

\subsection{Radioactive lodine therapy with HSCT for NB}

The norepinephrine analog metaiodobenzylguanidine (MIBG) is selectively accumulated in sympathetic nervous tissue, and several clinical studies of high dose iodine-131-labeled MIBG (131 I-MIBG) in combination with myeloablative chemotherapy and Auto HSCT for the treatment of NB were performed. Although this regimen has acceptable toxicity (Yanik et al., 2002), six of 22 assessable patients had complete or partial remission and the 3-year EFS and survival rates were $31 \% \pm 10 \%$ and $58 \% \pm 10 \%$ (Yanik et al., 2002). A case of ${ }^{131}$ I-MIBG therapy with reduced intensity Allo HSCT in recurrent extensive neuroblastoma was also reported. This patient achieved remission which was maintained for 3 months after transplantation (Takahashi et al., 2008). A study of high-dose 131I-MIBG with T cell-depleted haplo-identical HSCT and post-transplant immunotherapy in children with relapsed or refractory NB shows durable remission. All five patients in this study had no acute GVHD and four patients who received additional treatment with donor lymphocyte infusion (DLI) developed controllable chronic GVHD after DLI. Analysis of immunologic recovery showed a fast reappearance of NK- and T-cells. Two patients are alive with no evidence of disease 40 and 42 months after transplantation (Toporski et al., 2009). A phase I trial in which patients 
with refractory or relapsed NB received double ${ }^{131} \mathrm{I}-\mathrm{MIBG}$ infusions (target red marrow radiation index ranged from 22 to $50 \mathrm{mCi} / \mathrm{kg}$ ) at 2-week intervals with Auto HSCT 2 weeks after the second dose was reported. This regimen had no dose-limiting toxicities and dose intensification of ${ }^{131}$ I-MIBG. The PFS at 6 and 12 months was $57 \pm 11 \%$ and $33 \pm 11 \%$, respectively (Matthay et al., 2009).

\section{Brain tumors}

Brain tumors are the most common pediatric malignant tumors with various types and various grades of malignancy. Recent advances in multidisciplinary treatment have improved the OS of pediatric brain tumors, especially chemotherapy-sensitive high-grade malignant tumors such as medulloblastoma (MB) or primitive neuroectodermal tumors (PNET). Many studies of HSCT were undertaken for high-grade pediatric brain tumors that are both chemotherapy-sensitive and resistant. Initial HSCT studies for high-grade glioma and ependymoma, which are relatively chemotherapy-resistant, failed to show an efficient clinical effect (Grill et al., 1996; Kalifa et al., 1992), although HSCT for patients with high-risk MB played an important role in improving survival (Gajjar \& Pizer, 2010). Recently, molecular targeted therapies for adult high-grade gliomas and various grades of pediatric glioma or ependymoma are being studied (Tsuruta et al., 2011a). The combination of molecular therapy and HSCT may be of special interest in such chemotherapy-resistant cases.

\subsection{Conditioning regimens \& stem cell sources of HSCT for brain tumors}

Until the early 1990's, high-dose 1,3-bis(2-chloroethyl)-1-nitrosourea (BCNU) based regimens followed by Auto BMT were utilized for high-risk brain tumors, especially for high-grade glioma in adults. In 1979, the first use of intensive BCNU and Auto BMT for brain tumors was reported with doses of $900 \mathrm{mg} / \mathrm{m}^{2}$ and $1500 \mathrm{mg} / \mathrm{m}^{2}$ (Phillips et al., 1979). Subsequent reports of single treatment BCNU showed the limiting dose of BCNU ranges from 600 to 1,200 mg/m² (Hochberg et al., 1981; Phillips et al., 1983). Although several studies of high-dose BCNU treatment for high-grade glioma showed responses (Hochberg et al., 1981) or prolonged survival when compared with historical control groups (Johnson et al., 1987), the effects were thought to be limited by late toxicity (Phillips et al., 1986). In France, an analysis of high-dose BCNU $\left(800 \mathrm{mg} / \mathrm{m}^{2}\right)$ single treatment followed by Auto HSCT $($ BMT $=84$, PBSCT $=30)$ and local irradiation $(60 \mathrm{~Gy})$ for patients (median age, 44 years) with supratentorial high-grade glioma (glioblastoma $(\mathrm{GB})=78$, anaplastic astrocytoma $(\mathrm{AA})=24$, anaplastic oligodendroglioma $(\mathrm{OD})=12$ ) was performed. With 89 months of median follow-up, the OS was 12 months for GB, 37 months for OD, and 81 months for AA. There were some long-term survivors, although OS was comparable to that described for other treatments (Durando et al., 2003). A BCNU combination regimen (BCNU $600 \mathrm{mg} / \mathrm{m}^{2}$, thiotepa $900 \mathrm{mg} / \mathrm{m}^{2}$, and etoposide 1,500 or $750 \mathrm{mg} / \mathrm{m}^{2}$ ) followed by BMT and local irradiation was studied in 42 relatively young patients (median age, 12.2 years) with high-risk brain tumors at 10 academic oncology centers in the US, UK, and Australia. Of 25 $(G B=20)$ evaluable newly diagnosed patients, $20 \%$ achieved $C R$ and $4 \%$ partial remission (PR), while $28 \%$ remained in continuing complete remission (CCR) and $44 \%$ remained with stable disease prior to radiation therapy Of eight $(\mathrm{GB}=3)$ evaluable patients with recurrent disease, one $(G B=1)$ achieved $C R$ and two $(G B=1) P R$, while one $(G B=1)$ remained in CCR and four with stable disease for 1 to 110.2 months (Papadakis et al., 2000). 
A Phase II study of high-dose busulfan $\left(150 \mathrm{mg} / \mathrm{m}^{2}\right.$ daily for 4 days) and thiotepa (350 $\mathrm{mg} / \mathrm{m}^{2}$ daily for 3 days) followed by BMT in children with recurrent brain tumors was designed in France. In 20 children (median age, 6 years), five partial responses (3/6 MB, 1/5 ependymoma, 1/2 PNET), three objective responses, ten cases of stable disease, and one case of progressive disease were observed, although one patient died due to toxicity. There were high levels of toxicity in terms of aphasia and cutaneous, hepatic, and neurological complications (Kalifa et al., 1992). Subsequent studies of regimens of thiotepa + etoposide, cyclophosphamide + melphalan, busulfan + melphalan, carboplatin + etoposide, and thiotepa + melphalan followed by BMT (or PBSCT) in patients with high-risk brain tumors reported some long-term survivors, including some patients with recurrent tumors (Finlay et al., 1996; Graham et al., 1997; Hara et al., 1998; Mahoney et al., 1996). In patients with recurrent tumors, long-term survivors usually have local recurrence, and patients with disseminated tumors have very poor prognosis (Graham et al., 1997)

Recently, a study of low-dose continuous intravenous etoposide (day -22 to day -2 ) along with high-dose carboplatin $\left(667 \mathrm{mg} / \mathrm{m}^{2}\right.$ daily or area under the curve (AUC) $=9$ $\mathrm{mg} / \mathrm{ml} / \mathrm{min}$ for 3 days) and thiotepa $\left(300 \mathrm{mg} / \mathrm{m}^{2}\right.$ daily for 3 days) followed by HSCT conducted in patients with recurrent malignant brain tumors reported that some patients had long-term survival (Grodman et al., 2009).

\subsection{HSCT \& type of brain tumors}

HSCT was often considered in patients with high-risk (e.g. metastatic or disseminated) or recurrent MB. The Children's Cancer Group in the US reported 23 patients with recurrent MB who were treated with Auto HSCT and a conditioning regimen consisting of carboplatin, thiotepa, and etoposide. This resulted in long-term survivors; the EFS and OS were $34 \pm 10 \%$ and $46 \pm 11 \%$, respectively, at 36 months post-HSCT (Dunkel et al., 1998). In Spain, 19 patients with high-risk $(n=13)$ and recurrent $(n=6) \mathrm{MB}$ and supratentorial PNET were treated with high-dose busulfan and melphalan followed by Auto HSCT. The 2-year EFS was $38 \pm 14 \%$ in all patients and $57 \pm 15 \%$ for the high-risk group (Perez-Martinez et al., 2005). In France, high-dose busulfan and thiotepa with HSCT followed by posterior fossa irradiation for local MB recurrence or progression after conventional chemotherapy was studied in 39 children (median age at diagnosis, 31 months) and was showed to yield a high OS rate $(68.8 \%$ at 5 years; $95 \%$ CI: $53.0-81.2 \%$ ) (Ridola et al., 2007). A risk-adapted craniospinal radiotherapy (23.4-39.6 Gy) followed by high-dose HSCT (St Jude Medulloblastoma-96) performed at St. Jude Children's Research Hospital also showed an improved outcome (Gajjar et al., 2006). Patients aged < 3 years at diagnosis had a better outcome (Shih et al., 2008). Pre-relapse definitive radiation therapy is thought to be one of the prognostic factors for recurrent MB. HDC is not effective in patients with recurrent MB who received cranial radiation therapy prior to recurrence (Gururangan et al., 2008; Massimino et al., 2009).

In the 1990s, two studies of HDC (thiotepa, busulfan, etoposide, and carboplatin) followed by HSCT for patients with recurrent ependymoma failed to show clinical efficacy (Grill et al., 1996; Mason et al., 1998). On the other hand, for patients with relapsed or progressive central nervous system germ cell tumors, thiotepa-based HDC regimens followed by HSCT were studied. Patients with germinomas have better outcomes than patients with nongerminomatous germ cell tumors (Modak et al., 2004).

Central nervous system atypical teratoid/rhabdoid tumors (CNS AT/RT) are rare tumors of childhood with a very poor prognosis. Median survival of CNS AT/RT is less than 1 year 
with conventional therapy. One study involving high-dose carboplatin, thiotepa, and etoposide followed by HSCT was performed in 13 patients with CNS AT/RT after tumor resection and conventional chemotherapy consisting of cisplatin, vincristine, cyclophosphamide, and etoposide with or without high-dose methotrexate. Three of seven patients who received the high-dose methotrexate combined HSCT regimen had long-term remission $(42+, 54+$, and $67+$ months), although they received no radiation therapy (Gardner et al., 2008). Trilateral retinoblastoma is also a rare brain tumor in the pineal region with very poor prognosis. HDC for trilateral retinoblastoma has some effect (De Ioris et al., 2010; Dunkel et al., 2010b), even if the tumor has relapsed (Tsuruta et al., 2011b).

\subsection{HSCT for young children with brain tumors}

HSCT is often considered for young children with newly diagnosed MB instead of radiation therapy because cranial irradiation in young children is thought to incur late complications (Kim et al., 2010). In the US, the Memorial Sloan-Kettering Cancer Center study of HDC followed by Auto BMT for young children with newly diagnosed malignant brain tumors shortened the period of maintenance chemotherapy and reduced the risk of radiation therapy and had some long survivors (Mason et al., 1998). The neuropsychological findings of patients who received BMT revealed within low average range of intelligence (Sands et al., 1998). They also studied Auto BMT for young children with recurrent malignant tumors and showed that HDC with BMT followed by additional external-beam irradiation is effective for some young children with recurrent malignant tumors (Guruangan et al., 1998). Patients with supratentorial PNET have poor outcomes when compared to MB. HDC followed by HSCT in young patients with newly diagnosed supratentorial PNET provides improved EFS and OS and radiation therapy for these patients can sometimes be deferred or eliminated (Fangusaro et al., 2008).

\subsection{Tandem \& allo HSCT for brain tumors}

Tandem HSCT is performed for brain tumors as well as neuroblastoma. Two courses of high-dose melphalan $\left(100 \mathrm{mg} / \mathrm{m}^{2}\right)$ with PBSCT in 16 patients with cerebral PNET safely resulted in a high response rate, i.e. $11 \mathrm{PR}$ in 14 patients with measurable disease (Vassal et al., 2001). A study of children with newly diagnosed MB and supratentorial PNET who were treated with four cycles of high-dose cyclophosphamide $\left(4,000 \mathrm{mg} / \mathrm{m}^{2}\right)$, cisplatin $(75$ $\left.\mathrm{mg} / \mathrm{m}^{2}\right)$, and vincristine $\left(1.5 \mathrm{mg} / \mathrm{m}^{2} \times 2\right)$ with 49 of 53 patients completing all four cycles and HSCT showed a 2-year PFS rate of $73.7 \pm 10.5 \%$ for high-risk patients (residual tumor $\geq$ $1.5 \mathrm{~cm}^{2}$ after conventional therapy) and $93.6 \pm 4.7 \%$ for average-risk patients (Strother et al., 2001). In Korea, 18 patients with high-risk solid tumors including brain tumors received two courses of HDC (cyclophosphamide, melphalan, thiotepa, carboplatin, etoposide, etc.) with HSCT. In this study, all patients with MB were alive and disease-free, although patients with other types of brain tumors died (Sung et al., 2003). Our case report series showed that double HDC consisting of melphalan and thiotepa may cure patients with primary disseminated $\mathrm{MB}$; however, a patient with high expression of erythroblastic leukemia viral oncogene homolog 2 (ERBB2) relapsed (Aihara et al., 2010). Recently, there is a report that single HSCT regimens have greater toxicity than $\geq 3$ tandem HSCT which use milder HDC per HSCT cycle (Panosyan et al., 2011).

Allo HSCT for brain tumors is still experimental, although there are case reports from 1992 (Lundberg et al., 1992; Tsuruta et al., 2011b). An antitumor GVT effect associated with 
chronic GVHD was observed in a patient with metastatic MB after Allo HSCT, (Secondino et al., 2008).

\section{Ewing's sarcoma}

Studies of Auto BMT for patients with Ewing's sarcoma (ES) were reported in both adults and children since the early 1980s. In initial studies of Auto BMT for ESwing, melphalanbased conditioning regimens were used for disseminated or relapsed patients, with some achieving remission (Cornbleet et al., 1981; Graham-Pole et al., 1984). Subsequent studies of Auto HSCT for ES involved regimens combined with TBI or busulfan.

\subsection{TBI combined regimens for ES}

Until the 1990s, TBI-combined regimens were often utilized. Regimens consisting of TBI (12 Gy), melphalan, and etoposide with or without carboplatin for multi-focal or relapsed ES showed better outcomes (relapse-free survival $45 \pm 12 \%$ at 6 years) when compared with historical controls (Burdach et al., 1993). For patients with high-risk ES in first CR, HSCT with or without TBI was associated with a DFS of $62.7 \pm 11 \%$ overall and $40 \pm 21.9 \%$ for those with metastatic disease (Madero et al., 1998). One study of HSCT with versus without TBI for patients with primary metastatic (stage IV) ES $(n=171)$ showed improved prognosis (overall EFS $40 \%$ vs. 19\%), although patients with pulmonary or skeletal metastases had especially poor outcome (EFS $27 \%$ vs. 0\%) (Paulussen et al., 1998). HSCT with TBI for patients with ES did not improve the prognosis of patients with metastases to bone or bone marrow; the majority experienced relapse and died with progressive disease (Kushner \& Meyers, 2001; Meyers et al., 2001). Recurrent ES also has a poor prognosis. However, in secondary remission HSCT can improve the prognosis of recurrent ES (Barker et al., 2005).

\subsection{Busulfan \& melphalan regimens for ES}

Since the late 1990s busulfan has been often utilized instead of TBI. Studies of melphalanbased conditioning regimens including busulfan were reported from several groups. In 21 children with high-risk ES resistant to conventional therapy and recurrent disease, PBSCT with melphalan-based regimens did not show any benefit (Drabko et al., 2005). In a study of 33 recurrent or progressive ES patients treated with regimens of high-dose busulfan or melphalan with or without TBI, some patients achieved long-term survival although the treatment was associated severe toxicity (McTiernan et al., 2006). In 2006, in Europe the benefits of high-dose busulfan $\left(600 \mathrm{mg} / \mathrm{m}^{2}\right)$ and melphalan $\left(140 \mathrm{mg} / \mathrm{m}^{2}\right)$ for ES with metastasis to lung or bone without bone marrow involvement were shown (Oberlin et al., 2006). The subsequent Euro-EWING-99 trial reported an estimated 3-year EFS of $45 \%$ in 46 children younger than 14 years with primary disseminated multifocal ES (Ladenstein et al., 2010). Recently, an Italian and Scandinavian group showed the effectiveness of HSCT with busulfan and melphalan for patients with non-metastatic, poor-response ES (5-year EFS of HSCT and non-HSCT group was 72\% and 33\%) (Ferrari et al., 2011).

\subsection{Tandem HSCT for ES}

The European Intergroup Cooperative Ewing Sarcoma Study (EICESS) compared the regimen of HyperME (TBI 12 Gy, melphalan 120 to $180 \mathrm{mg} / \mathrm{m}^{2}$, etoposide 40 to $60 \mathrm{mg} / \mathrm{kg}$, and carboplatin maximum dose $1,800 \mathrm{mg}$ ) to TandemME (two cycles of melphalan 120 to 
$140 \mathrm{mg} / \mathrm{m}^{2}$ and etoposide $60 \mathrm{mg} / \mathrm{kg}$ ). The 5-year EFS of Hyper ME and TandemME were 22 $\pm 8 \%$ and $29 \pm 9 \%$, respectively, while the lethal complication rate was $23 \%$ in HyperME and $4 \%$ in TandemME (Burdach et al., 2003). A study using two cycles of alkylating agent-based HDC for primary metastatic bulky disease or recurrent ES showed acceptable toxicities and OS of $45 \%$ and EFS of $47 \%$ at 3 years, although only $65 \%$ of patients were able to proceed to the second cycle (Rosenthal et al., 2008).

\subsection{Allo HSCT for ES}

From EICESS, 26 cases of Auto HSCT and 10 cases of Allo HSCT for multifocal or recurrent advanced ES were reported. Although patients who received Allo HSCT failed to show allogeneic immunological effects e.g. GVT, eight of 26 cases with Auto HSCT received systemic interleukin-2 (IL-2) therapy after HSCT. The IL-2 group had a better EFS rate $(60 \pm$ $18 \%)$ compared to the groups that received Allo HSCT (20 $\pm 13 \%)$ alone or Auto HSCT alone $(22 \pm 13 \%)$ (Burdach et al., 2000). A case report of a 6 year-old girl with multifocal ES who received Allo HSCT from her HLA-matched mother showed a shrinkage of her pulmonary tumors and grade 1 GVHD during a taper of the immunosuppression (Lucas et al., 2008). Recently, reduced- versus high-intensity conditioning for Allo HSCT was compared. There was no improvement in survival with reduced intensity conditioning due to an increased rate of death caused by disease and relapse (Thiel et al., 2011).

\section{Osteosarcoma}

The prognosis of metastatic or relapsed osteosarcoma is very poor. High-dose methotrexate has been used since the 1970s, but HSCT for osteosarcoma remains experimental. There are fewer reports of HSCT for osteosarcoma than for ES since patients with metastatic or recurrent disease have $<20 \%$ chance of long-term survival despite aggressive treatment (Chou et al., 2008). However, many kinds of new agents including antifolate compounds and muramyl tripeptide phosphatidylethanolamine are under investigation (Jaffe, 2009).

The initial study of HSCT in two cases of advanced osteosarcoma failed to reveal a clinical effect. In 2001, the Cooperative German-Austrian-Swiss Osteosarcoma Study Group reported the results of HSCT in 15 patients with relapsed osteosarcoma. Three of the 15 patients died of toxic complications and the treatment outcome was not better than with conventional therapy (Sauerbrey et al., 2001). A study using tandem HSCT for relapsed osteosarcoma by the Italian Sarcoma Group Study showed two points: only patients who are chemosensitive to induction treatment can obtain complete remission after HSCT, and the length of remission is short (Fagioli et al., 2002). From Japan, two case reports of Allo HSCT for osteosarcoma were presented. In the first case, non-myeloablative chemotherapy followed by PBSCT for a third CR showed a GVT effect in reduction of the metastatic lung lesion with GVHD (Kounami et al., 2005). In the second report, a patient with progressive osteosarcoma and multiple lung and bone metastases received TBI combined with myeloablative HCT (thiotepa $600 \mathrm{mg} / \mathrm{m}^{2}$ and etoposide $1,000 \mathrm{mg} / \mathrm{m}^{2}$ ) followed by Allo BMT. The metastatic lesions successfully disappeared (Goi et al., 2006).

\section{Wilms' tumor}

Although multidisciplinary therapies including chemotherapy improved the cure rate of Wilms' tumor (WT) to approximately $80-85 \%$, the EFS in recurrent disease was less than 
15\% before HDC with HSCT was developed (Grundy et al., 1989). Furthermore, a number of adverse prognostic factors related to poor outcomes during relapse have been identified and are used as inclusion criteria for studies involving HSCT (Dallorso et al., 2008) e.g. loss of heterozygosity in chromosomes 1p and 16q (Grundy et al., 2005).

The European Bone Marrow Transplantation for Solid Tumor Registry reported a study of 25 children with WT (12 stage IV, 5 stage III, 3 stage II, and 1 stage I) who were treated with Auto BMT and melphalan-based or other regimens. Of 21 recurrent cases, 13 achieved second or subsequent CR after Auto BMT and eight patients were event-free at 14-90 months (Garaventa et al., 1994). High-dose melphalan, etoposide, and carboplatin (MEC) followed by Auto HSCT in high-risk recurrent WT patients with chemotherapy-responsive disease was evaluated prospectively by the French Society of Pediatric Oncology. The DFS and OS at 3 years were $50 \pm 17 \%$ and $60 \pm 18 \%$, respectively (Pein et al., 1998). A report of 23 patients with high-risk WT, including 20 recurrent cases, treated with HDC including MEC followed by Auto HSCT in the German Cooperative Wilms Tumor Studies showed an estimated survival and EFS are $60.9 \%$ and $48.2 \%$ (Kremens et al., 2002). At the Children's Memorial Hospital in Chicago, one or two cycles of HSCT were tried in patients with relapsed WT. The EFS and OS of this study at 4 years were $60 \%$ and $73 \%$, respectively (Campbell et al., 2004). A study in Italy also showed the benefit of Auto HSCT for high-risk relapsed WT with a 3-year DFS approaching 50\% (Spreafico et al., 2008). A meta-analysis of 6 studies with or without HDC followed by Auto HSCT revealed that patients who only relapsed in the lung have a higher survival rate than those who relapsed in other locations. The 4-year survival rate among stage I or II patients was about $30 \%$ higher in the no HSCT group than the HSCT group, but the 4-year survival rate was similar in HSCT vs. no-HSCT in stage III and IV patients. These findings suggest that salvage chemotherapy is typically the better choice for relapsed WT patients, and that HSCT could be considered for stage III or IV patients with relapse only in the lungs (Presson et al., 2010). There is a case report describing a refractory case of WT with lung metastasis being cured by CBT (Massimino et al., 2010). There are rare case reports of WT successfully treated by HSCT, e.g. a case of third remission (Brown et al., 2010), a bilateral Wilms' tumor treated without any irradiation (Saarinen-Pihkala et al., 1998), and an anephric pediatric case with multiple recurrent WT treated in conjunction with hemodialysis (Dagher et al., 1998).

\section{Rhabdomyosarcoma}

Since the end of 1990s, the prognosis of patients with localized rhabdomyosarcoma (RS) has improved with an EFS rate of approximately $70 \%$. Although HDC with or without TBI followed by Auto or Allo HSCT has been performed for patients with metastatic or recurrent diseases by several groups, a retrospective multi-center analysis with 36 patients by the German and Austrian Pediatric Bone Marrow Transplantation Group in 1997 showed that the effect of HSCT was uncertain. In this study, the EFS rate at 2 years after HDC in 26 patients who were treated with MEC with or without TBI regimen was $36 \pm 7 \%$, and none of the 5 patients who received Allo BMT alive (Koscielniak et al., 1997). The European Intergroup MMT4-89 (including 4 cycles of standard chemotherapy) and MMT4-91 (melphalan-based HDC followed by HSCT after three courses of standard chemotherapy) studies on childhood metastatic RS suggested that there was prolonged survival with the MMT4-91 regimen (EFS and OS at 3 years were $29.7 \%$ and $40 \%$, respectively) when compared with the MMT4-89 regimen (EFS and OS at 3 year were $19.2 \%$ and $27.7 \%$, 
respectively) (Carli et al., 1999). However, their final report concluded there is no evidence that consolidation HDC improves outcomes (Carli et al., 2004). The analysis of 177 patients with stage IV RS from 22 studies who received HSCT also concluded that HSCT for patients with relapsed or refractory high-risk RS does not provide a significant advantage (Weigel et al., 2001). A recent meta-analysis of three non-randomized controlled studies on survival showed 3-year OS ranged from $22 \%$ to $55 \%$ in the HSCT group versus $18 \%$ to $55 \%$ in the control group, and also showed no differences between treatments (Peinemann et al., 2011). On the other hand, an analysis of HSCT for high-risk RS according to histological type suggested that for unfavorable histologies (alveolar or undifferentiated subtypes) HSCT after relapse may have some benefit because long-term survivors were sometimes seen (Stiff et al., 2010).

\section{Hepatoblastoma}

HCT followed by Auto or Allo HSCT for patients with high-risk hepatoblastoma (HB) was tried by several groups. The initial report described three patients with stage II or III HB who achieved CR after receiving Auto HSCT, and one patient with a third relapse showed PR (Hara et al., 1998). HSCT for MRD may improve survival (Yoshinari et al., 1998). Subsequent reports of tandem HSCT for three high-risk patients (metastatic or recurrent disease) showed that they failed to remain in remission (Katzenstein et al., 2002). Recent reports by the Japanese Study Group for Pediatric Liver Tumors also showed that the prognosis of HDC with HSCT for metastatic HB was poor (5-year OS of 43.9\%) (Hishiki et al., 2011). On the other hand, a report of a patient with recurrent metastatic HB who received non-myeloablative HSCT from a HLA-matched unrelated donor showed a probable GVT effect with GVHD (Inaba et al., 2006).

\section{Retinoblastoma}

The prognosis of retinoblastoma improved to a 5-year survival rate of approximately $90 \%$ through early diagnosis and proper treatment, including enucleation, chemotherapy, or radiation therapy. However, the outcome of progressive disease, i.e. optic nerve invasion, extra-ocular extension, or metastatic disease, especially into central nervous system (CNS), remains poor (Ali et al., 2011; Chantada et al., 2007; Cozza et al., 2009). Since the 1980s, HDC with HSCT with or without TBI has been performed with immunomagnetic purging (Saleh et al., 1988), or monitoring of MRD in the BM or PB by monoclonal antibody of 3A7 (Saarinen et al., 1991) or protein gene product 9.5 gene expression (Yamane et al., 1999) because retinoblastoma frequently infiltrates into these sites (Karcioglu et al., 1997). Several trials of Auto HSCT for metastatic retinoblastoma with or without CNS involvement were reported. Patients without CNS involvement were successfully treated by HDC followed by HSCT with or without local irradiation (Dunkel et al., 2000; Kremens et al., 2003; Matsubara et al., 2005). A patient with recurrent disseminated retinoblastoma in the lymph nodes, bone, and BM was successfully treated by HDC with CD34-selected Auto HSCT (Hertzberg et al., 2001). High-dose carboplatin ( 250 or $350 \mathrm{mg} / \mathrm{m}^{2}$ daily for 5 days), etoposide (350 $\mathrm{mg} / \mathrm{m}^{2}$ daily for 5 days), and cyclophosphamide ( $1.6 \mathrm{~g} / \mathrm{m}^{2}$ daily for 4 days), followed by HSCT, can improve survival in retinoblastoma involving bone or BM but not the CNS (Namouni et al., 1997). A patient with cerebrospinal fluid metastasis who received HSCT with high-dose/short-infusion cyclosporine to inhibit P-glycoprotein, which is expressed by 
most metastatic retinoblastomas, achieved long-term remission (Dimaras et al., 2009). A recent study of HDC with Auto HSCT for stage $4 \mathrm{~b}$ (CNS involvement) retinoblastoma showed some benefit for some patients with CNS metastasis (Dunkel et al., 2010a). Furthermore, a study of HDCT in South America for metastatic retinoblastoma with CNS involvement also showed that 2 of 4 patients with CNS involvement were alive and disease free at 39 and 27 months (Dunkel et al., 2010a). Tandem HSCT was attempted to treat advanced bilateral retinoblastoma. Nine patients with bilateral retinoblastoma received two cycles of HDC with regimens of MEC + BM (busulfan and melphalan) or CTE (carboplatin, thiotepa, and etoposide) + CM (cyclophosphamide and melphalan) followed by Auto HSCT in order to avoid external-beam radiation therapy. All patients had at least one functional eye and in two patients both eyes were preserved (Lee et al., 2008).

\section{References}

Aihara Y.; Tsuruta, T.; Kawamata, T., et al. (2010). Double High-Dose Chemotherapy Followed by Autologous Peripheral Blood Stem Cell Transplantation for Primary Disseminated Medulloblastoma: A Report of 3 Cases, J Pediatr Hematol Oncol, Vol.32, 2, pp. e70-74

Ali M.J.; Reddy, V.A.; Honavar, S.G., et al. (2011). Orbital Retinoblastoma: Where Do We Go from Here?, J Cancer Res Ther, Vol.7, 1, pp. 11-14

Ash S.; Gigi, V.; Askenasy, N., et al. (2009). Graft Versus Neuroblastoma Reaction Is Efficiently Elicited by Allogeneic Bone Marrow Transplantation through Cytolytic Activity in the Absence of GVHD, Cancer Immunol Immunother, Vol.58, 12, pp. 20732084

Ash S.; Stein, J.; Askenasy, N., et al. (2010). Immunomodulation with Dendritic Cells and Donor Lymphocyte Infusion Converge to Induce Graft Vs Neuroblastoma Reactions without GVHD after Allogeneic Bone Marrow Transplantation, $\mathrm{Br} \mathrm{J}$ Cancer, Vol.103, 10, pp. 1597-1605

August C.S.; Serota, F.T.; Koch, P.A., et al. (1984). Treatment of Advanced Neuroblastoma with Supralethal Chemotherapy, Radiation, and Allogeneic or Autologous Marrow Reconstitution, J Clin Oncol, Vol.2, 6, pp. 609-616

Barker L.M.; Pendergrass, T.W.; Sanders, J.E., et al. (2005). Survival after Recurrence of Ewing's Sarcoma Family of Tumors, J Clin Oncol, Vol.23, 19, pp. 4354-4362

Bensimhon P.; Villablanca, J.G.; Sender, L.S., et al. (2010). Peripheral Blood Stem Cell Support for Multiple Cycles of Dose Intensive Induction Therapy Is Feasible with Little Risk of Tumor Contamination in Advanced Stage Neuroblastoma: A Report from the Childrens Oncology Group, Pediatr Blood Cancer, Vol.54, 4, pp. 596-602

Berthold F.; Boos, J.; Burdach, S., et al. (2005). Myeloablative Megatherapy with Autologous Stem-Cell Rescue Versus Oral Maintenance Chemotherapy as Consolidation Treatment in Patients with High-Risk Neuroblastoma: A Randomised Controlled Trial, Lancet Oncol, Vol.6, 9, pp. 649-658

Brodeur G.M.; Pritchard, J.; Berthold, F., et al. (1993). Revisions of the International Criteria for Neuroblastoma Diagnosis, Staging, and Response to Treatment, J Clin Oncol, Vol.11, 8, pp. 1466-1477 
Brodeur G.M.; Seeger, R.C.; Schwab, M., et al. (1984). Amplification of N-Myc in Untreated Human Neuroblastomas Correlates with Advanced Disease Stage, Science, Vol.224, 4653, pp. 1121-1124

Brown E.; Hebra, A.; Jenrette, J., et al. (2010). Successful Treatment of Late, Recurrent Wilms Tumor with High-Dose Chemotherapy and Autologous Stem Cell Rescue in Third Complete Response, J Pediatr Hematol Oncol, Vol.32, 6, pp. e241-243

Burdach S.; Jurgens, H.; Peters, C., et al. (1993). Myeloablative Radiochemotherapy and Hematopoietic Stem-Cell Rescue in Poor-Prognosis Ewing's Sarcoma, J Clin Oncol, Vol.11, 8, pp. 1482-1488

Burdach S.; Meyer-Bahlburg, A.; Laws, H.J., et al. (2003). High-Dose Therapy for Patients with Primary Multifocal and Early Relapsed Ewing's Tumors: Results of Two Consecutive Regimens Assessing the Role of Total-Body Irradiation, J Clin Oncol, Vol.21, 16, pp. 3072-3078

Burdach S.; van Kaick, B.; Laws, H.J., et al. (2000). Allogeneic and Autologous Stem-Cell Transplantation in Advanced Ewing Tumors. An Update after Long-Term Followup from Two Centers of the European Intergroup Study Eicess. Stem-Cell Transplant Programs at Dusseldorf University Medical Center, Germany and St. Anna Kinderspital, Vienna, Austria, Ann Oncol, Vol.11, 11, pp. 1451-1462

Campbell A.D.; Cohn, S.L.; Reynolds, M., et al. (2004). Treatment of Relapsed Wilms' Tumor with High-Dose Therapy and Autologous Hematopoietic Stem-Cell Rescue: The Experience at Children's Memorial Hospital, J Clin Oncol, Vol.22, 14, pp. 2885-2890

Carli M.; Colombatti, R.; Oberlin, O., et al. (2004). European Intergroup Studies (MMT4-89 and MMT4-91) on Childhood Metastatic Rhabdomyosarcoma: Final Results and Analysis of Prognostic Factors, J Clin Oncol, Vol.22, 23, pp. 4787-4794

Carli M.; Colombatti, R.; Oberlin, O., et al. (1999). High-Dose Melphalan with Autologous Stem-Cell Rescue in Metastatic Rhabdomyosarcoma, J Clin Oncol, Vol.17, 9, pp. 2796-2803

Chantada G.L.; Dunkel, I.J.; Antoneli, C.B., et al. (2007). Risk Factors for Extraocular Relapse Following Enucleation after Failure of Chemoreduction in Retinoblastoma, Pediatr Blood Cancer, Vol.49, 3, pp. 256-260

Chou A.J.Geller, D.S. \& Gorlick, R. (2008). Therapy for Osteosarcoma: Where Do We Go from Here?, Paediatr Drugs, Vol.10, 5, pp. 315-327

Cohn S.L.; Moss, T.J.; Hoover, M., et al. (1997). Treatment of Poor-Risk Neuroblastoma Patients with High-Dose Chemotherapy and Autologous Peripheral Stem Cell Rescue, Bone Marrow Transplant, Vol.20, 7, pp. 543-551

Cornbleet M.A.; Corringham, R.E.; Prentice, H.G., et al. (1981). Treatment of Ewing's Sarcoma with High-Dose Melphalan and Autologous Bone Marrow Transplantation, Cancer Treat Rep, Vol.65, 3-4, pp. 241-244

Cozza R.; De Ioris, M.A.; Ilari, I., et al. (2009). Metastatic Retinoblastoma: Single Institution Experience over Two Decades, Br J Ophthalmol, Vol.93, 9, pp. 1163-1166

Dagher R.; Kreissman, S.; Robertson, K.A., et al. (1998). High Dose Chemotherapy with Autologous Peripheral Blood Progenitor Cell Transplantation in an Anephric Child with Multiply Recurrent Wilms Tumor, J Pediatr Hematol Oncol, Vol.20, 4, pp. 357360 
Dallorso S.; Dini, G.; Faraci, M., et al. (2008). SCT for Wilms' Tumour, Bone Marrow Transplant, Vol.41 Suppl 2, pp. S128-130

De Ioris M.A.; Fidani, P.; Munier, F.L., et al. (2010). Successful Treatment of Trilateral Retinoblastoma with Conventional and High-Dose Chemotherapy Plus Radiotherapy: A Case Report, J Pediatr Hematol Oncol, Vol.32, 8, pp. e343-345

Dimaras H.; Heon, E.; Budning, A., et al. (2009). Retinoblastoma CSF Metastasis Cured by Multimodality Chemotherapy without Radiation, Ophthalmic Genet, Vol.30, 3, pp. 121-126

Drabko K.; Zawitkowska-Klaczynska, J.; Wojcik, B., et al. (2005). Megachemotherapy Followed by Autologous Stem Cell Transplantation in Children with Ewing's Sarcoma, Pediatr Transplant, Vol.9, 5, pp. 618-621

Dunkel I.J.; Aledo, A.; Kernan, N.A., et al. (2000). Successful Treatment of Metastatic Retinoblastoma, Cancer, Vol.89, 10, pp. 2117-2121

Dunkel I.J.; Boyett, J.M.; Yates, A., et al. (1998). High-Dose Carboplatin, Thiotepa, and Etoposide with Autologous Stem-Cell Rescue for Patients with Recurrent Medulloblastoma. Children's Cancer Group, J Clin Oncol, Vol.16, 1, pp. 222-228

Dunkel I.J.; Chan, H.S.; Jubran, R., et al. (2010a). High-Dose Chemotherapy with Autologous Hematopoietic Stem Cell Rescue for Stage 4B Retinoblastoma, Pediatr Blood Cancer, Vol.55, 1, pp. 149-152

Dunkel I.J.; Jubran, R.F.; Gururangan, S., et al. (2010b). Trilateral Retinoblastoma: Potentially Curable with Intensive Chemotherapy, Pediatr Blood Cancer, Vol.54, 3, pp. 384-387

Durando X.; Lemaire, J.J.; Tortochaux, J., et al. (2003). High-Dose BCNU Followed by Autologous Hematopoietic Stem Cell Transplantation in Supratentorial HighGrade Malignant Gliomas: A Retrospective Analysis of 114 Patients, Bone Marrow Transplant, Vol.31, 7, pp. 559-564

Evans A.E.; August, C.S.; Kamani, N., et al. (1994). Bone Marrow Transplantation for High Risk Neuroblastoma at the Children's Hospital of Philadelphia: An Update, Med Pediatr Oncol, Vol.23, 4, pp. 323-327

Fagioli F.; Aglietta, M.; Tienghi, A., et al. (2002). High-Dose Chemotherapy in the Treatment of Relapsed Osteosarcoma: An Italian Sarcoma Group Study, J Clin Oncol, Vol.20, 8, pp. 2150-2156

Fangusaro J.; Finlay, J.; Sposto, R., et al. (2008). Intensive Chemotherapy Followed by Consolidative Myeloablative Chemotherapy with Autologous Hematopoietic Cell Rescue (AuHCR) in Young Children with Newly Diagnosed Supratentorial Primitive Neuroectodermal Tumors (sPNETs): Report of the Head Start I and Ii Experience, Pediatr Blood Cancer, Vol.50, 2, pp. 312-318

Ferrari S.; Sundby Hall, K.; Luksch, R., et al. (2011). Nonmetastatic Ewing Family Tumors: High-Dose Chemotherapy with Stem Cell Rescue in Poor Responder Patients. Results of the Italian Sarcoma Group/Scandinavian Sarcoma Group III Protocol, Ann Oncol, Vol.22, 5, pp. 1221-1227

Finlay J.L.; Goldman, S.; Wong, M.C., et al. (1996). Pilot Study of High-Dose Thiotepa and Etoposide with Autologous Bone Marrow Rescue in Children and Young Adults with Recurrent CNS Tumors. The Children's Cancer Group, J Clin Oncol, Vol.14, 9, pp. 2495-2503 
Fish J.D. \& Grupp, S.A. (2008). Stem Cell Transplantation for Neuroblastoma, Bone Marrow Transplant, Vol.41, 2, pp. 159-165

Gajjar A.; Chintagumpala, M.; Ashley, D., et al. (2006). Risk-Adapted Craniospinal Radiotherapy Followed by High-Dose Chemotherapy and Stem-Cell Rescue in Children with Newly Diagnosed Medulloblastoma (St Jude Medulloblastoma-96): Long-Term Results from a Prospective, Multicentre Trial, Lancet Oncol, Vol.7, 10, pp. 813-820

Gajjar A. \& Pizer, B. (2010). Role of High-Dose Chemotherapy for Recurrent Medulloblastoma and Other CNS Primitive Neuroectodermal Tumors, Pediatr Blood Cancer, Vol.54, 4, pp. 649-651

Garaventa A.; Hartmann, O.; Bernard, J.L., et al. (1994). Autologous Bone Marrow Transplantation for Pediatric Wilms' Tumor: The Experience of the European Bone Marrow Transplantation Solid Tumor Registry, Med Pediatr Oncol, Vol.22, 1, pp. 1114

Gardner S.L.; Asgharzadeh, S.; Green, A., et al. (2008). Intensive Induction Chemotherapy Followed by High Dose Chemotherapy with Autologous Hematopoietic Progenitor Cell Rescue in Young Children Newly Diagnosed with Central Nervous System Atypical Teratoid Rhabdoid Tumors, Pediatr Blood Cancer, Vol.51, 2, pp. 235-240

George R.E.; Li, S.; Medeiros-Nancarrow, C., et al. (2006). High-Risk Neuroblastoma Treated with Tandem Autologous Peripheral-Blood Stem Cell-Supported Transplantation: Long-Term Survival Update, J Clin Oncol, Vol.24, 18, pp. 2891-2896

Goi K.; Inukai, T.; Honna, H., et al. (2011). Successful Tandem (Autologous-Cord Blood) SCT in Advanced Neuroblastomas with Highly Amplified Mycn, Bone Marrow Transplant, Vol.46, 6, pp. 835-839

Goi K.; Sugita, K.; Tezuka, T., et al. (2006). A Successful Case of Allogeneic Bone Marrow Transplantation for Osteosarcoma with Multiple Metastases of Lung and Bone, Bone Marrow Transplant, Vol.37, 1, pp. 115-116

Graham M.L.; Herndon, J.E., 2nd; Casey, J.R., et al. (1997). High-Dose Chemotherapy with Autologous Stem-Cell Rescue in Patients with Recurrent and High-Risk Pediatric Brain Tumors, J Clin Oncol, Vol.15, 5, pp. 1814-1823

Graham-Pole J.; Lazarus, H.M.; Herzig, R.H., et al. (1984). High-Dose Melphalan Therapy for the Treatment of Children with Refractory Neuroblastoma and Ewing's Sarcoma, Am J Pediatr Hematol Oncol, Vol.6, 1, pp. 17-26

Grill J.; Kalifa, C.; Doz, F., et al. (1996). A High-Dose Busulfan-Thiotepa Combination Followed by Autologous Bone Marrow Transplantation in Childhood Recurrent Ependymoma. A Phase-II Study, Pediatr Neurosurg, Vol.25, 1, pp. 7-12

Grodman H.Wolfe, L. \& Kretschmar, C. (2009). Outcome of Patients with Recurrent Medulloblastoma or Central Nervous System Germinoma Treated with Low Dose Continuous Intravenous Etoposide Along with Dose-Intensive Chemotherapy Followed by Autologous Hematopoietic Stem Cell Rescue, Pediatr Blood Cancer, Vol.53, 1, pp. 33-36

Grundy P.; Breslow, N.; Green, D.M., et al. (1989). Prognostic Factors for Children with Recurrent Wilms' Tumor: Results from the Second and Third National Wilms' Tumor Study, J Clin Oncol, Vol.7, 5, pp. 638-647 
Grundy P.E.; Breslow, N.E.; Li, S., et al. (2005). Loss of Heterozygosity for Chromosomes 1p and 16q Is an Adverse Prognostic Factor in Favorable-Histology Wilms Tumor: A Report from the National Wilms Tumor Study Group, J Clin Oncol, Vol.23, 29, pp. 7312-7321

Grupp S.A.; Stern, J.W.; Bunin, N., et al. (2000). Rapid-Sequence Tandem Transplant for Children with High-Risk Neuroblastoma, Med Pediatr Oncol, Vol.35, 6, pp. 696-700

Guruangan S.; Dunkel, I.J.; Goldman, S., et al. (1998). Myeloablative Chemotherapy with Autologous Bone Marrow Rescue in Young Children with Recurrent Malignant Brain Tumors, J Clin Oncol, Vol.16, 7, pp. 2486-2493

Gururangan S.; Krauser, J.; Watral, M.A., et al. (2008). Efficacy of High-Dose Chemotherapy or Standard Salvage Therapy in Patients with Recurrent Medulloblastoma, Neuro Oncol, Vol.10, 5, pp. 745-751

Hara J.; Osugi, Y.; Ohta, H., et al. (1998). Double-Conditioning Regimens Consisting of Thiotepa, Melphalan and Busulfan with Stem Cell Rescue for the Treatment of Pediatric Solid Tumors, Bone Marrow Transplant, Vol.22, 1, pp. 7-12

Hertzberg H.; Kremens, B.; Velten, I., et al. (2001). Recurrent Disseminated Retinoblastoma in a 7-Year-Old Girl Treated Successfully by High-Dose Chemotherapy and CD34Selected Autologous Peripheral Blood Stem Cell Transplantation, Bone Marrow Transplant, Vol.27, 6, pp. 653-655

Hishiki T.; Matsunaga, T.; Sasaki, F., et al. (2011). Outcome of Hepatoblastomas Treated Using the Japanese Study Group for Pediatric Liver Tumor (JPLT) Protocol-2: Report from the JPLT, Pediatr Surg Int, Vol.27, 1, pp. 1-8

Hobbie W.L.; Moshang, T.; Carlson, C.A., et al. (2008). Late Effects in Survivors of Tandem Peripheral Blood Stem Cell Transplant for High-Risk Neuroblastoma, Pediatr Blood Cancer, Vol.51, 5, pp. 679-683

Hochberg F.H.; Parker, L.M.; Takvorian, T., et al. (1981). High-Dose BCNU with Autologous Bone Marrow Rescue for Recurrent Glioblastoma Multiforme, J Neurosurg, Vol.54, 4, pp. $455-460$

Holtta P.; Alaluusua, S.; Saarinen-Pihkala, U.M., et al. (2002). Long-Term Adverse Effects on Dentition in Children with Poor-Risk Neuroblastoma Treated with High-Dose Chemotherapy and Autologous Stem Cell Transplantation with or without Total Body Irradiation, Bone Marrow Transplant, Vol.29, 2, pp. 121-127

Hovi L.; Saarinen-Pihkala, U.M.; Vettenranta, K., et al. (1999). Growth in Children with Poor-Risk Neuroblastoma after Regimens with or without Total Body Irradiation in Preparation for Autologous Bone Marrow Transplantation, Bone Marrow Transplant, Vol.24, 10, pp. 1131-1136

Inaba H.; Handgretinger, R.; Furman, W., et al. (2006). Allogeneic Graft-VersusHepatoblastoma Effect, Pediatr Blood Cancer, Vol.46, 4, pp. 501-505

Inoue M.; Nakano, T.; Yoneda, A., et al. (2003). Graft-Versus-Tumor Effect in a Patient with Advanced Neuroblastoma Who Received HLA Haplo-Identical Bone Marrow Transplantation, Bone Marrow Transplant, Vol.32, 1, pp. 103-106

Jaffe N. (2009). Osteosarcoma: Review of the Past, Impact on the Future. The American Experience, Cancer Treat Res, Vol.152, pp. 239-262 
Johnson D.B.; Thompson, J.M.; Corwin, J.A., et al. (1987). Prolongation of Survival for HighGrade Malignant Gliomas with Adjuvant High-Dose Bcnu and Autologous Bone Marrow Transplantation, J Clin Oncol, Vol.5, 5, pp. 783-789

Jubert C.; Wall, D.A.; Grimley, M., et al. (2011). Engraftment of Unrelated Cord Blood after Reduced-Intensity Conditioning Regimen in Children with Refractory Neuroblastoma: A Feasibility Trial, Bone Marrow Transplant, Vol.46, 2, pp. 232-237

Kalifa C.; Hartmann, O.; Demeocq, F., et al. (1992). High-Dose Busulfan and Thiotepa with Autologous Bone Marrow Transplantation in Childhood Malignant Brain Tumors: A Phase II Study, Bone Marrow Transplant, Vol.9, 4, pp. 227-233

Kamani N.; August, C.S.; Bunin, N., et al. (1996). A Study of Thiotepa, Etoposide and Fractionated Total Body Irradiation as a Preparative Regimen Prior to Bone Marrow Transplantation for Poor Prognosis Patients with Neuroblastoma, Bone Marrow Transplant, Vol.17, 6, pp. 911-916

Karcioglu Z.A.; al-Mesfer, S.A.; Abboud, E., et al. (1997). Workup for Metastatic Retinoblastoma. A Review of 261 Patients, Ophthalmology, Vol.104, 2, pp. 307-312

Katzenstein H.M.; Rigsby, C.; Shaw, P.H., et al. (2002). Novel Therapeutic Approaches in the Treatment of Children with Hepatoblastoma, J Pediatr Hematol Oncol, Vol.24, 9, pp. 751-755

Kim S.Y.; Sung, K.W.; Hah, J.O., et al. (2010). Reduced-Dose Craniospinal Radiotherapy Followed by High-Dose Chemotherapy and Autologous Stem Cell Rescue for Children with Newly Diagnosed High-Risk Medulloblastoma or Supratentorial Primitive Neuroectodermal Tumor, Korean J Hematol, Vol.45, 2, pp. 120-126

Kletzel M.; Katzenstein, H.M.; Haut, P.R., et al. (2002). Treatment of High-Risk Neuroblastoma with Triple-Tandem High-Dose Therapy and Stem-Cell Rescue: Results of the Chicago Pilot II Study, J Clin Oncol, Vol.20, 9, pp. 2284-2292

Koscielniak E.; Klingebiel, T.H.; Peters, C., et al. (1997). Do Patients with Metastatic and Recurrent Rhabdomyosarcoma Benefit from High-Dose Therapy with Hematopoietic Rescue? Report of the German/Austrian Pediatric Bone Marrow Transplantation Group, Bone Marrow Transplant, Vol.19, 3, pp. 227-231

Kounami S.; Nakayama, K.; Yoshiyama, M., et al. (2005). Non-Myeloablative Allogenic Peripheral Blood Stem Cell Transplantation in a Patient with Refractory Osteosarcoma, Pediatr Transplant, Vol.9, 3, pp. 342-345

Kremens B.; Gruhn, B.; Klingebiel, T., et al. (2002). High-Dose Chemotherapy with Autologous Stem Cell Rescue in Children with Nephroblastoma, Bone Marrow Transplant, Vol.30, 12, pp. 893-898

Kremens B.; Wieland, R.; Reinhard, H., et al. (2003). High-Dose Chemotherapy with Autologous Stem Cell Rescue in Children with Retinoblastoma, Bone Marrow Transplant, Vol.31, 4, pp. 281-284

Kushner B.H. \& Meyers, P.A. (2001). How Effective Is Dose-Intensive/Myeloablative Therapy against Ewing's Sarcoma/Primitive Neuroectodermal Tumor Metastatic to Bone or Bone Marrow? The Memorial Sloan-Kettering Experience and a Literature Review, J Clin Oncol, Vol.19, 3, pp. 870-880

Kushner B.H.; O'Reilly, R.J.; Mandell, L.R., et al. (1991). Myeloablative Combination Chemotherapy without Total Body Irradiation for Neuroblastoma, J Clin Oncol, Vol.9, 2, pp. 274-279 
Ladenstein R.; Lasset, C.; Hartmann, O., et al. (1994). Comparison of Auto Versus Allografting as Consolidation of Primary Treatments in Advanced Neuroblastoma over One Year of Age at Diagnosis: Report from the European Group for Bone Marrow Transplantation, Bone Marrow Transplant, Vol.14, 1, pp. 37-46

Ladenstein R.; Potschger, U.; Le Deley, M.C., et al. (2010). Primary Disseminated Multifocal Ewing Sarcoma: Results of the Euro-Ewing 99 Trial, J Clin Oncol, Vol.28, 20, pp. 3284-3291

Laprie A.; Michon, J.; Hartmann, O., et al. (2004). High-Dose Chemotherapy Followed by Locoregional Irradiation Improves the Outcome of Patients with International Neuroblastoma Staging System Stage II and III Neuroblastoma with Mycn Amplification, Cancer, Vol.101, 5, pp. 1081-1089

Lee S.H.; Yoo, K.H.; Sung, K.W., et al. (2008). Tandem High-Dose Chemotherapy and Autologous Stem Cell Rescue in Children with Bilateral Advanced Retinoblastoma, Bone Marrow Transplant, Vol.42, 6, pp. 385-391

Lucas K.G.Schwartz, C. \& Kaplan, J. (2008). Allogeneic Stem Cell Transplantation in a Patient with Relapsed Ewing Sarcoma, Pediatr Blood Cancer, Vol.51, 1, pp. 142-144

Lundberg J.H.; Weissman, D.E.; Beatty, P.A., et al. (1992). Treatment of Recurrent Metastatic Medulloblastoma with Intensive Chemotherapy and Allogeneic Bone Marrow Transplantation, J Neurooncol, Vol.13, 2, pp. 151-155

Madero L.; Munoz, A.; Sanchez de Toledo, J., et al. (1998). Megatherapy in Children with High-Risk Ewing's Sarcoma in First Complete Remission, Bone Marrow Transplant, Vol.21, 8, pp. 795-799

Mahoney D.H., Jr.; Strother, D.; Camitta, B., et al. (1996). High-Dose Melphalan and Cyclophosphamide with Autologous Bone Marrow Rescue for Recurrent/Progressive Malignant Brain Tumors in Children: A Pilot Pediatric Oncology Group Study, J Clin Oncol, Vol.14, 2, pp. 382-388

Marabelle A.; Merlin, E.; Halle, P., et al. (2011). Cd34+ Immunoselection of Autologous Grafts for the Treatment of High-Risk Neuroblastoma, Pediatr Blood Cancer, Vol.56, 1, pp. 134-142

Marabelle A.; Paillard, C.; Tchirkov, A., et al. (2007). Graft-Versus-Tumour Effect in Refractory Metastatic Neuroblastoma, Bone Marrow Transplant, Vol.39, 12, pp. 809810

Mason W.P.; Grovas, A.; Halpern, S., et al. (1998). Intensive Chemotherapy and Bone Marrow Rescue for Young Children with Newly Diagnosed Malignant Brain Tumors, J Clin Oncol, Vol.16, 1, pp. 210-221

Massimino M.Cohen, K.J. \& Finlay, J.L. (2010). Is There a Role for Myeloablative Chemotherapy with Autologous Hematopoietic Cell Rescue in the Management of Childhood High-Grade Astrocytomas?, Pediatr Blood Cancer, Vol.54, 4, pp. 641-643

Massimino M.; Gandola, L.; Spreafico, F., et al. (2009). No Salvage Using High-Dose Chemotherapy Plus/Minus Reirradiation for Relapsing Previously Irradiated Medulloblastoma, Int J Radiat Oncol Biol Phys, Vol.73, 5, pp. 1358-1363

Matsubara H.; Makimoto, A.; Higa, T., et al. (2005). A Multidisciplinary Treatment Strategy That Includes High-Dose Chemotherapy for Metastatic Retinoblastoma without Cns Involvement, Bone Marrow Transplant, Vol.35, 8, pp. 763-766 
Matthay K.K.; Quach, A.; Huberty, J., et al. (2009). Iodine-131--Metaiodobenzylguanidine Double Infusion with Autologous Stem-Cell Rescue for Neuroblastoma: A New Approaches to Neuroblastoma Therapy Phase I Study, J Clin Oncol, Vol.27, 7, pp. 1020-1025

Matthay K.K.; Seeger, R.C.; Reynolds, C.P., et al. (1994). Allogeneic Versus Autologous Purged Bone Marrow Transplantation for Neuroblastoma: A Report from the Childrens Cancer Group, J Clin Oncol, Vol.12, 11, pp. 2382-2389

Matthay K.K.; Villablanca, J.G.; Seeger, R.C., et al. (1999). Treatment of High-Risk Neuroblastoma with Intensive Chemotherapy, Radiotherapy, Autologous Bone Marrow Transplantation, and 13-Cis-Retinoic Acid. Children's Cancer Group, N Engl J Med, Vol.341, 16, pp. 1165-1173

McCowage G.B.; Vowels, M.R.; Shaw, P.J., et al. (1995). Autologous Bone Marrow Transplantation for Advanced Neuroblastoma Using Teniposide, Doxorubicin, Melphalan, Cisplatin, and Total-Body Irradiation, J Clin Oncol, Vol.13, 11, pp. 27892795

McTiernan A.; Driver, D.; Michelagnoli, M.P., et al. (2006). High Dose Chemotherapy with Bone Marrow or Peripheral Stem Cell Rescue Is an Effective Treatment Option for Patients with Relapsed or Progressive Ewing's Sarcoma Family of Tumours, Ann Oncol, Vol.17, 8, pp. 1301-1305

Meyers P.A.; Krailo, M.D.; Ladanyi, M., et al. (2001). High-Dose Melphalan, Etoposide, Total-Body Irradiation, and Autologous Stem-Cell Reconstitution as Consolidation Therapy for High-Risk Ewing's Sarcoma Does Not Improve Prognosis, J Clin Oncol, Vol.19, 11, pp. 2812-2820

Modak S.; Gardner, S.; Dunkel, I.J., et al. (2004). Thiotepa-Based High-Dose Chemotherapy with Autologous Stem-Cell Rescue in Patients with Recurrent or Progressive Cns Germ Cell Tumors, J Clin Oncol, Vol.22, 10, pp. 1934-1943

Molina B.; Alonso, L.; Gonzalez-Vicent, M., et al. (2011). High-Dose Busulfan and Melphalan as Conditioning Regimen for Autologous Peripheral Blood Progenitor Cell Transplantation in High-Risk Neuroblastoma Patients, Pediatr Hematol Oncol, Vol.28, 2, pp. 115-123

Namouni F.; Doz, F.; Tanguy, M.L., et al. (1997). High-Dose Chemotherapy with Carboplatin, Etoposide and Cyclophosphamide Followed by a Haematopoietic Stem Cell Rescue in Patients with High-Risk Retinoblastoma: A Sfop and Sfgm Study, Eur J Cancer, Vol.33, 14, pp. 2368-2375

Navid F.Armstrong, M. \& Barfield, R.C. (2009). Immune Therapies for Neuroblastoma, Cancer Biol Ther, Vol.8, 10, pp. 874-882

Oberlin O.; Rey, A.; Desfachelles, A.S., et al. (2006). Impact of High-Dose Busulfan Plus Melphalan as Consolidation in Metastatic Ewing Tumors: A Study by the Societe Francaise Des Cancers De L'enfant, J Clin Oncol, Vol.24, 24, pp. 3997-4002

Panosyan E.H.; Ikeda, A.K.; Chang, V.Y., et al. (2011). High-Dose Chemotherapy with Autologous Hematopoietic Stem-Cell Rescue for Pediatric Brain Tumor Patients: A Single Institution Experience from Ucla, J Transplant, Vol.2011, pp. e740673

Papadakis V.; Dunkel, I.J.; Cramer, L.D., et al. (2000). High-Dose Carmustine, Thiotepa and Etoposide Followed by Autologous Bone Marrow Rescue for the Treatment of High 
Risk Central Nervous System Tumors, Bone Marrow Transplant, Vol.26, 2, pp. 153160

Paulussen M.; Ahrens, S.; Burdach, S., et al. (1998). Primary Metastatic (Stage IV) Ewing Tumor: Survival Analysis of 171 Patients from the Eicess Studies. European Intergroup Cooperative Ewing Sarcoma Studies, Ann Oncol, Vol.9, 3, pp. 275-281

Pedrazzoli P.; Da Prada, G.A.; Giorgiani, G., et al. (2002). Allogeneic Blood Stem Cell Transplantation after a Reduced-Intensity, Preparative Regimen: A Pilot Study in Patients with Refractory Malignancies, Cancer, Vol.94, 9, pp. 2409-2415

Pein F.; Michon, J.; Valteau-Couanet, D., et al. (1998). High-Dose Melphalan, Etoposide, and Carboplatin Followed by Autologous Stem-Cell Rescue in Pediatric High-Risk Recurrent Wilms' Tumor: A French Society of Pediatric Oncology Study, J Clin Oncol, Vol.16, 10, pp. 3295-3301

Peinemann F.; Kroger, N.; Bartel, C., et al. (2011). High-Dose Chemotherapy Followed by Autologous Stem Cell Transplantation for Metastatic Rhabdomyosarcoma--a Systematic Review, PLoS One, Vol.6, 2, pp. e17127

Perez-Martinez A.; Lassaletta, A.; Gonzalez-Vicent, M., et al. (2005). High-Dose Chemotherapy with Autologous Stem Cell Rescue for Children with High Risk and Recurrent Medulloblastoma and Supratentorial Primitive Neuroectodermal Tumors, J Neurooncol, Vol.71, 1, pp. 33-38

Philip T.; Ladenstein, R.; Zucker, J.M., et al. (1993). Double Megatherapy and Autologous Bone Marrow Transplantation for Advanced Neuroblastoma: The LMCE2 Study, $\mathrm{Br}$ J Cancer, Vol.67, 1, pp. 119-127

Phillips G.L.; Fay, J.W.; Herzig, G.P., et al. (1983). Intensive 1,3-Bis(2-Chloroethyl)-1Nitrosourea (BCNU), NSC \#4366650 and Cryopreserved Autologous Marrow Transplantation for Refractory Cancer. A Phase I-II Study, Cancer, Vol.52, 10, pp. 1792-1802

Phillips G.L.; Fay, J.W.; Herzig, G.P., et al. (1979). Intensive 1,3-Bis(2-Chloroethyl)-1Nitrosourea (BCNU) Autologous Bone Marrow Transplantation Therapy of Refractory Cancer: A Preliminary Report, Exp Hematol, Vol.7 Suppl 5, pp. 372-383

Phillips G.L.; Wolff, S.N.; Fay, J.W., et al. (1986). Intensive 1,3-Bis (2-Chloroethyl)-1Nitrosourea (BCNU) Monochemotherapy and Autologous Marrow Transplantation for Malignant Glioma, J Clin Oncol, Vol.4, 5, pp. 639-645

Presson A.Moore, T.B. \& Kempert, P. (2010). Efficacy of High-Dose Chemotherapy and Autologous Stem Cell Transplant for Recurrent Wilms' Tumor: A Meta-Analysis, J Pediatr Hematol Oncol, Vol.32, 6, pp. 454-461

Pritchard J.; Cotterill, S.J.; Germond, S.M., et al. (2005). High Dose Melphalan in the Treatment of Advanced Neuroblastoma: Results of a Randomised Trial (ENSG-1) by the European Neuroblastoma Study Group, Pediatr Blood Cancer, Vol.44, 4, pp. 348-357

Qayed M.; Chiang, K.Y.; Ricketts, R., et al. (2011). Tandem Stem Cell Rescue as Consolidation Therapy for High-Risk Neuroblastoma, Pediatr Blood Cancer, doi: 10.1002/pbc.23155. [Epub]

Ridola V.; Grill, J.; Doz, F., et al. (2007). High-Dose Chemotherapy with Autologous Stem Cell Rescue Followed by Posterior Fossa Irradiation for Local Medulloblastoma 
Recurrence or Progression after Conventional Chemotherapy, Cancer, Vol.110, 1, pp. 156-163

Rosenthal J.; Bolotin, E.; Shakhnovits, M., et al. (2008). High-Dose Therapy with Hematopoietic Stem Cell Rescue in Patients with Poor Prognosis Ewing Family Tumors, Bone Marrow Transplant, Vol.42, 5, pp. 311-318

Saarinen U.M.Sariola, H. \& Hovi, L. (1991). Recurrent Disseminated Retinoblastoma Treated by High-Dose Chemotherapy, Total Body Irradiation, and Autologous Bone Marrow Rescue, Am J Pediatr Hematol Oncol, Vol.13, 3, pp. 315-319

Saarinen-Pihkala U.M.Wikstrom, S. \& Vettenranta, K. (1998). Maximal Preservation of Renal Function in Patients with Bilateral Wilms' Tumor: Therapeutic Strategy of Late Kidney-Sparing Surgery and Replacement of Radiotherapy by High-Dose Melphalan and Stem Cell Rescue, Bone Marrow Transplant, Vol.22, 1, pp. 53-59

Saleh R.A.; Gross, S.; Cassano, W., et al. (1988). Metastatic Retinoblastoma Successfully Treated with Immunomagnetic Purged Autologous Bone Marrow Transplantation, Cancer, Vol.62, 11, pp. 2301-2303

Sands S.A.van Gorp, W.G. \& Finlay, J.L. (1998). Pilot Neuropsychological Findings from a Treatment Regimen Consisting of Intensive Chemotherapy and Bone Marrow Rescue for Young Children with Newly Diagnosed Malignant Brain Tumors, Childs Nerv Syst, Vol.14, 10, pp. 587-589

Sauerbrey A.; Bielack, S.; Kempf-Bielack, B., et al. (2001). High-Dose Chemotherapy (HDC) and Autologous Hematopoietic Stem Cell Transplantation (ASCT) as Salvage Therapy for Relapsed Osteosarcoma, Bone Marrow Transplant, Vol.27, 9, pp. 933-937

Secondino S.; Pedrazzoli, P.; Schiavetto, I., et al. (2008). Antitumor Effect of Allogeneic Hematopoietic Sct in Metastatic Medulloblastoma, Bone Marrow Transplant, Vol.42, 2, pp. 131-133

Shih C.S.; Hale, G.A.; Gronewold, L., et al. (2008). High-Dose Chemotherapy with Autologous Stem Cell Rescue for Children with Recurrent Malignant Brain Tumors, Cancer, Vol.112, 6, pp. 1345-1353

Shimada H.; Ambros, I.M.; Dehner, L.P., et al. (1999). The International Neuroblastoma Pathology Classification (the Shimada System), Cancer, Vol.86, 2, pp. 364-372

Spreafico F.; Bisogno, G.; Collini, P., et al. (2008). Treatment of High-Risk Relapsed Wilms Tumor with Dose-Intensive Chemotherapy, Marrow-Ablative Chemotherapy, and Autologous Hematopoietic Stem Cell Support: Experience by the Italian Association of Pediatric Hematology and Oncology, Pediatr Blood Cancer, Vol.51, 1, pp. 23-28

Stiff P.J.; Agovi, M.A.; Antman, K.H., et al. (2010). High-Dose Chemotherapy with Blood or Bone Marrow Transplants for Rhabdomyosarcoma, Biol Blood Marrow Transplant, Vol.16, 4, pp. 525-532

Strother D.; Ashley, D.; Kellie, S.J., et al. (2001). Feasibility of Four Consecutive High-Dose Chemotherapy Cycles with Stem-Cell Rescue for Patients with Newly Diagnosed Medulloblastoma or Supratentorial Primitive Neuroectodermal Tumor after Craniospinal Radiotherapy: Results of a Collaborative Study, J Clin Oncol, Vol.19, 10, pp. 2696-2704 
Sung K.W.; Lee, S.H.; Yoo, K.H., et al. (2007). Tandem High-Dose Chemotherapy and Autologous Stem Cell Rescue in Patients over 1 Year of Age with Stage 4 Neuroblastoma, Bone Marrow Transplant, Vol.40, 1, pp. 37-45

Sung K.W.; Yoo, K.H.; Chung, E.H., et al. (2003). Successive Double High-Dose Chemotherapy with Peripheral Blood Stem Cell Rescue Collected During a Single Leukapheresis Round in Patients with High-Risk Pediatric Solid Tumors: A Pilot Study in a Single Center, Bone Marrow Transplant, Vol.31, 6, pp. 447-452

Takahashi H.; Manabe, A.; Aoyama, C., et al. (2008). Iodine-131-Metaiodobenzylguanidine Therapy with Reduced-Intensity Allogeneic Stem Cell Transplantation in Recurrent Neuroblastoma, Pediatr Blood Cancer, Vol.50, 3, pp. 676-678

Thiel U.; Wawer, A.; Wolf, P., et al. (2011). No Improvement of Survival with ReducedVersus High-Intensity Conditioning for Allogeneic Stem Cell Transplants in Ewing Tumor Patients, Ann Oncol, Vol.22, 7, pp. 1614-1621

Toporski J.; Garkavij, M.; Tennvall, J., et al. (2009). High-Dose Iodine-131Metaiodobenzylguanidine with Haploidentical Stem Cell Transplantation and Posttransplant Immunotherapy in Children with Relapsed/Refractory Neuroblastoma, Biol Blood Marrow Transplant, Vol.15, 9, pp. 1077-1085

Trager C.; Kogner, P.; Lindskog, M., et al. (2003). Quantitative Analysis of Tyrosine Hydroxylase mRNA for Sensitive Detection of Neuroblastoma Cells in Blood and Bone Marrow, Clin Chem, Vol.49, 1, pp. 104-112

Tsuruta T.; Aihara, Y.; Kanno, H., et al. (2011a). Shared Molecular Targets in Pediatric Gliomas and Ependymomas, Pediatr Blood Cancer, doi: 10.1002/pbc.23009. [Epub]

Tsuruta T.; Aihara, Y.; Kanno, H., et al. (2011b). High-Dose Chemotherapy Followed by Autologous and Allogeneic Peripheral Blood Stem Cell Transplantation for Recurrent Disseminated Trilateral Retinoblastoma, Childs Nerv Syst, Vol.27, 6, pp. 1019-1024

Vanlemmens P.; Plouvier, E.; Amsallem, D., et al. (1992). Transplantation of Umbilical Cord Blood in Neuroblastoma, Nouv Rev Fr Hematol, Vol.34, 3, pp. 243-246

Vassal G.; Tranchand, B.; Valteau-Couanet, D., et al. (2001). Pharmacodynamics of Tandem High-Dose Melphalan with Peripheral Blood Stem Cell Transplantation in Children with Neuroblastoma and Medulloblastoma, Bone Marrow Transplant, Vol.27, 5, pp. 471-477

Wagner J.E. (1993). Umbilical Cord Blood Stem Cell Transplantation, Am J Pediatr Hematol Oncol, Vol.15, 2, pp. 169-174

Weigel B.J.; Breitfeld, P.P.; Hawkins, D., et al. (2001). Role of High-Dose Chemotherapy with Hematopoietic Stem Cell Rescue in the Treatment of Metastatic or Recurrent Rhabdomyosarcoma, J Pediatr Hematol Oncol, Vol.23, 5, pp. 272-276

Weinstein J.L.Katzenstein, H.M. \& Cohn, S.L. (2003). Advances in the Diagnosis and Treatment of Neuroblastoma, Oncologist, Vol.8, 3, pp. 278-292

Yalcin B.; Kremer, L.C.; Caron, H.N., et al. (2011). High-Dose Chemotherapy and Autologous Haematopoietic Stem Cell Rescue for Children with High-Risk Neuroblastoma, Cochrane Database Syst Rev, Vol.2011, 5, pp. CD006301

Yamane S.; Shirai, C.; Arimoto, A., et al. (1999). Disseminated Retinoblastoma Successfully Treated with Myeloablative Chemotherapy--Implication for Molecular Detection of Minimal Residual Disease, Bone Marrow Transplant, Vol.23, 9, pp. 971-974 
Yanik G.A.; Levine, J.E.; Matthay, K.K., et al. (2002). Pilot Study of Iodine-131Metaiodobenzylguanidine in Combination with Myeloablative Chemotherapy and Autologous Stem-Cell Support for the Treatment of Neuroblastoma, J Clin Oncol, Vol.20, 8, pp. 2142-2149

Yoshinari M.; Imaizumi, M.; Hayashi, Y., et al. (1998). Peripheral Blood Stem Cell Transplantation for Hepatoblastoma with Microscopical Residue: A Therapeutic Approach for Incompletely Resected Tumor, Tohoku J Exp Med, Vol.184, 3, pp. 247254 


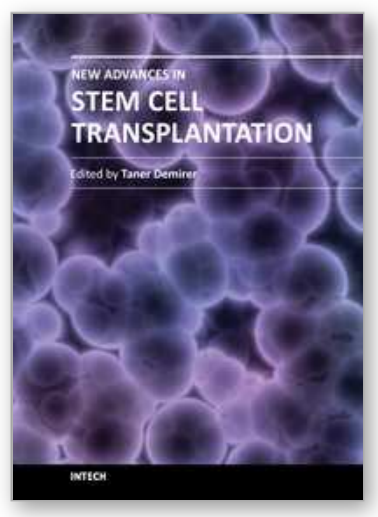

\author{
New Advances in Stem Cell Transplantation \\ Edited by Prof. Taner Demirer
}

ISBN 978-953-51-0013-3

Hard cover, 582 pages

Publisher InTech

Published online 24, February, 2012

Published in print edition February, 2012

This book documents the increased number of stem cell-related research, clinical applications, and views for the future. The book covers a wide range of issues in cell-based therapy and regenerative medicine, and includes clinical and preclinical chapters from the respected authors involved with stem cell studies and research from around the world. It complements and extends the basics of stem cell physiology, hematopoietic stem cells, issues related to clinical problems, tissue typing, cryopreservation, dendritic cells, mesenchymal cells, neuroscience, endovascular cells and other tissues. In addition, tissue engineering that employs novel methods with stem cells is explored. Clearly, the continued use of biomedical engineering will depend heavily on stem cells, and this book is well positioned to provide comprehensive coverage of these developments.

\title{
How to reference
}

In order to correctly reference this scholarly work, feel free to copy and paste the following:

Toshihisa Tsuruta (2012). Hematopoietic Stem Cell Transplantation for Malignant Solid Tumors in Children, New Advances in Stem Cell Transplantation, Prof. Taner Demirer (Ed.), ISBN: 978-953-51-0013-3, InTech, Available from: http://www.intechopen.com/books/new-advances-in-stem-cell-transplantation/hematopoieticstem-cell-transplantation-for-malignant-solid-tumors-in-children

\section{INTECH}

open science | open minds

\section{InTech Europe}

University Campus STeP Ri

Slavka Krautzeka 83/A

51000 Rijeka, Croatia

Phone: +385 (51) 770447

Fax: +385 (51) 686166

www.intechopen.com

\section{InTech China}

Unit 405, Office Block, Hotel Equatorial Shanghai

No.65, Yan An Road (West), Shanghai, 200040, China

中国上海市延安西路65号上海国际贵都大饭店办公楼 405 单元

Phone: +86-21-62489820

Fax: +86-21-62489821 
(C) 2012 The Author(s). Licensee IntechOpen. This is an open access article distributed under the terms of the Creative Commons Attribution 3.0 License, which permits unrestricted use, distribution, and reproduction in any medium, provided the original work is properly cited. 